Pírez, P.Una aproximación sociológica al derecho a la ciudad. Derecho y Ciencias Sociales. Mayo- Octubre 2019 No 21. (Derecho, ciudad y propiedad) Pgs 6-22. ISNN 1852-2971. Instituto de Cultura Jurídica y Maestría en Sociología Jurídica. FCJ y S. UNLP

\title{
Una aproximación sociológica al derecho a la ciudad
}

\author{
A sociological approach to the right to the city
}

\section{Pedro Pírez}

\section{Resumen}

Este artículo propone una mirada desde las ciencias sociales al derecho a la ciudad, en tanto dimensión del objeto urbano que, en su relación con otras dimensiones, adquiere significación para su plena comprensión. Introduce en el análisis al derecho a la ciudad en tanto dimensión de la urbanización, o la ciudad, apuntando a identificar las condiciones de la dinámica de la urbanización que definen socialmente a ese derecho, en relación con dos componentes estructurales de la urbanización: mercantilización de su producción y consumo y propiedad privada. Componentes que configuran contradicciones estructurales con tal derecho.

En las sociedades latinoamericanas, el derecho a la ciudad implica el reconocimiento de un cruce de tensiones entre la reproducción económica y la reproducción social, y entre sus ámbitos espaciales. De allí las contradicciones entre el espacio urbano como bien de cambio y como bien de uso.

El ejercicio del derecho a la ciudad tiene una condición previa: la posibilidad de asentarse en el ámbito urbano. La preeminencia del acceso al suelo y a la vivienda. Esto significa el derecho al lugar en tanto ámbito de la vida social: bienes urbanos para su acceso y centralidad como relaciones e intercambios que hacen y renuevan la sociedad aglomerada. Ello supone una contradicción con la mercantilización de la urbanización y la propiedad privada a la vez que ese derecho se basa en la posibilidad de resolver tal contradicción.

Palabras clave: urbanización, derecho a la ciudad, mercantilización, propiedad privada, América Latina.

\begin{abstract}
This article proposes a view from the social sciences to the right to the city, as a dimension of the urban object that, in its relationship with other dimensions, acquires significance for its full understanding. This work introduces the right to the city as a dimension of urbanization, or of the city, aiming to identify the conditions of urbanization dynamics that socially define that right, in relation to two structural components of urbanization: commercialization of its production and consumption and private property. Components that make up structural contradictions with such a right.

In Latin American societies, the right to the city implies the recognition of a crossing of tensions between economic reproduction and social reproduction, and between their spatial spheres. Hence the contradictions between the urban space as a good for change and as a good for use.

The exercise of the right to the city has a precondition: the possibility of settling in the urban environment. The pre-eminence of access to land and housing. This means the right to place as a sphere of social life: urban goods for their access and centrality as relationships and exchanges that make and renew the agglomerated society. This supposes a contradiction with the commodification of urbanization and private property, while this right is based on the possibility of resolving this contradiction.
\end{abstract}

Keywords: urbanization, right to the city, commodification, privet property, Latin America.

\footnotetext{
- Doctor en Derecho y Ciencias Sociales por la Universidad Nacional de Córdoba, donde se graduó como Abogado y realizó posgrado en Sociología. Investigador Principal del CONICET con sede en el Instituto de Estudios de América Latina y el Caribe de la Facultad de Ciencias Sociales de la UBA. Profesor de posgrado en universidades nacionales y extranjeras. ptpirez@gmail.com.
}

Recibido: 1/3/2019. Publicable con correcciones: 8/7/2019. 
Pírez, P.Una aproximación sociológica al derecho a la ciudad. Derecho y Ciencias Sociales. Mayo- Octubre 2019 № 21. (Derecho, ciudad y propiedad) Pgs 6-22. ISNN 1852-2971. Instituto de Cultura Jurídica y Maestría en Sociología Jurídica. FCJ y S. UNLP

\section{Una aproximación sociológica al derecho a la ciudad}

Pedro Pírez

\section{Introducción}

Este artículo propone una mirada sobre el derecho a la ciudad desde los estudios sociales de la realidad urbana en las sociedades latinoamericanas, sin intentar hacer sociología del derecho aplicada a la cuestión urbana. ${ }^{1}$ No pretendemos desarrollar una cuestión jurídica sino un análisis de lo urbano en el que lo jurídico aparece como una dimensión del objeto de estudio, adquiriendo así su plena significación, necesaria para su comprensión.

La urbanización, la ciudad, es un objeto multidimensional, su estudio, incluyendo el que se hace dentro de la denominación de sociología urbana, se desarrolla a partir de los aportes de las ciencias sociales, en una atención multidisciplinaria. Esto significa que para conocer el objeto urbano es preciso acudir a varias disciplinas: antropología, derecho, economía, política, sociología, etc. Bajo el título de sociología urbana (en cursos o textos) encontramos el estudio de la urbanización o la ciudad desde los aportes de las ciencias sociales. El análisis propiamente sociológico de lo urbano da cuenta, fundamentalmente,de la relación entre desigualdades sociales y territoriales. $^{2}$

Este artículo se propone analizar una cuestión urbana, que parece haber penetrado desde lo jurídico, con una mirada de sociología urbana que, como aclaramos implica la puesta en acción de más de una disciplina de las ciencias sociales. Aunque se recurre a una noción introducida desde el campo jurídico, no fue inicialmenteincorporadadesde ese campo, sino que se inició como resultado de reflexiones sociológico-filosóficas sobre la ciudad.Es relevante mencionar aquí a Henry Lefebvre, para quien el derecho a la ciudad se concreta en la posibilidad de una amplia participación-integración en la heterogeneidad de las obras y los productos socialesurbanos. Participación de la centralidad urbana que, más que un lugar, es una posibilidad de integración (Lefebvre, 1969). De allí que como interpreta Granier (2012), esas formulaciones se enmarcan en un combate teórico y práctico contra la urbanización capitalista $\mathrm{y}$, particularmente, contra el modo de producción capitalista al que contribuye a reproducir. Esa formulación del derecho a la ciudad sería, a la vez, parte de una transición desde la mirada basada en el proletariado a la sustentada en la ciudadanía (Ibíd.).

\footnotetext{
${ }^{1}$ Un ejemplo de esa perspectiva es el trabajo de Azuela (1989).

${ }^{2}$ Ejemplos de esto se encuentran en los índices de los textos de "sociología urbana", como pueden ser los clásicos de Flanagan (1993) y Savage et al. (2003).
} 
Pírez, P.Una aproximación sociológica al derecho a la ciudad. Derecho y Ciencias Sociales. Mayo- Octubre 2019 № 21. (Derecho, ciudad y propiedad) Pgs 6-22. ISNN 1852-2971. Instituto de Cultura Jurídica y Maestría en Sociología Jurídica. FCJ y S. UNLP

En este trabajo, la incorporación del derecho a la ciudad implica la integración al análisis de la urbanización de ciertos componentes del sistema normativo que resultan de decisiones institucionales de poder y que se concretan en reglas formalmente definidas: leyes, decretos, etc.

La miradapropuesta intenta identificar las condiciones de la dinámica de la urbanización que definen socialmente al derecho a la ciudad. Para ello lo relacionamos con dos componentes estructurales: la mercantilización de su producción y consumo y la propiedad privada. ${ }^{3}$ Podemos adelantar que, según nuestra hipótesis, esos componentesconfiguran contradicciones estructurales con ese derecho.

Para este análisis,podemos coincidir con la nociónque ofrece laCarta Mundial sobre el Derecho a la Ciudad en su versión de 2005. Según la cual, se trata de

El usufructo equitativo de las ciudadesdentro de los principios de sustentabilidad, democracia, equidad y justiciasocial...derecho colectivo de los habitantes de las ciudades, en especial delos grupos vulnerables y desfavorecidos, que les confiere legitimidad de accióny de organización, basado en sus usos y costumbres, con el objetivo de alcanzarel pleno ejercicio del derecho a la libre autodeterminación y un nivel de vidaadecuado.(HIC, 2008:187.Énfasis nuestros)

Puede considerase parte de la ciudadanía, como posibilidadgeneralizada de accesoamplio a la vida social urbana (reproducción social aglomerada, calidad ambiental, producción y consumo cultural, territorio como identidad, decisiones políticas, etc.), que se basa en la disponibilidad de los soportes materiales (suelo, vivienda, infraestructuras, equipamientos) y funcionales (servicios) de la urbanización. ${ }^{4}$

La noción que aceptamos, que da una visión pragmática del derecho a la ciudad, tiene la ventaja de concretarlo en condiciones susceptibles de ser identificadas en las ciudades actuales. Pero, al mismo tiempo, la realización de esas condiciones, que permitirían la efectividad del derecho, no están muy alejadas de una crítica a la urbanización capitalista y a los componentes estructurales que, desde el modo de producción capitalista se imponen a esa urbanización.

Pensar el derecho a la ciudad enlas sociedades latinoamericanas conduce al reconocimiento de un cruce de tensiones entre los procesos de reproducción económica y los de reproducción

\footnotetext{
${ }^{3}$ Nos referimos a la propiedad privada individual que es la predominante en los regímenes jurídicos occidentales. ${ }^{4}$ Es imposible concebir la vida humana sin la existencia de soportes materiales y, particularmente, sin protección física frente a la gran vulnerabilidad de los seres humanos. Suelo y vivienda son, así, una condición básica de la vida humana.
} 
Pírez, P.Una aproximación sociológica al derecho a la ciudad. Derecho y Ciencias Sociales. Mayo- Octubre 2019 № 21. (Derecho, ciudad y propiedad) Pgs 6-22. ISNN 1852-2971. Instituto de Cultura Jurídica y Maestría en Sociología Jurídica. FCJ y S. UNLP

social (amplia), y entre sus ámbitos espaciales (Pírez, 2010). De allí las contradicciones entre el espacio urbano como bien de cambio y como bien de uso.

Esta manera de introducirnos en el derecho a la ciudad muestra la existencia de una condición inicial, previa: la posibilidad de asentarse en el ámbito urbano. Esto significa la preeminencia del acceso al suelo y a la vivienda. Esta condición puede entenderse comoun derecho al lugaren tanto ámbito particular de la vida social: bienes urbanos (suelo, vivienda, infraestructura, servicios, calidad ambiental, etc.) ycentralidad: ser parte del conjunto de relaciones e intercambios que hacen y renuevan la sociedad aglomerada.

Es por lo tanto posible considerar queesederecho se basa en la posibilidad de resolver lacontradicción que existeentre la necesidad delos bienes urbanos y las dificultades sociales para su acceso. De manera concreta, su contradicción con la mercantilización que hace depender elaccesoa esos bienes de la existencia de una demanda solvente. Lo que significa, consecuentemente, la tendencia a la exclusión de quienes no cuentan con los recursos monetarios suficientes para ello. Tensión que se consolida institucionalmente por medio de la aplicación del derecho de propiedad privada.

Esas dos dimensiones estructurales, mercantilización de la producción-consumo de la ciudad ypropiedad privada, son las dos vías por medio de las cuales desarrollamos nuestra reflexión.

Los contenidos de este artículo son el resultado de reflexiones producidas a partir de una investigación teórico-histórica sobre la urbanización en las sociedades latinoamericanas. Ese trabajo identificó la heterogeneidad de modalidades de producción-consumoque la caracterizan (Pírez, 2016a y 2016b), y que permitieron identificar las bases estructurales de su peculiaridad en nuestra región. Así, junto con el predominio de las modalidades mercantiles se percibe la relevancia de la producción no mercantil como alternativa de los sectores populares. Alternativa que supone, por una parte, acceso directo a la vivienda y, por la otra, reivindicación del acceso a la ciudad como derecho.

\section{EI Derecho a la Ciudad en la ciudad capitalista}

La proposición inicial puede ser formulada de esta manera: se accede a la ciudad (suelovivienda y demás bienes urbanos) como resultado del ejercicio de un derecho o como resultado de la capacidad económica (solvencia ${ }^{5}$ ) que permite pagar el precio de mercado de esos bienes. Más allá de la simplificación que supone esa fórmula, es posible afirmar que el predominio de

\footnotetext{
${ }^{5}$ El concepto de solvencia, definido en una relación solvencia/insolvencia es importante en estos razonamientos. Puede completarse su comprensión con otros dos textos: Pírez, 2016 y 2018.
} 
Pírez, P.Una aproximación sociológica al derecho a la ciudad. Derecho y Ciencias Sociales. Mayo- Octubre 2019 № 21. (Derecho, ciudad y propiedad) Pgs 6-22. ISNN 1852-2971. Instituto de Cultura Jurídica y Maestría en Sociología Jurídica. FCJ y S. UNLP

la mercantilización en la producción y consumo de la urbanización, estructuralmente determinado, tiende a impedir el acceso a la ciudad como derecho.

La consolidación de las relaciones capitalistas impuso la tendencia a una mercantilización universal del conjunto de los bienes y servicios (Esping-Andersen, 1993; Polanyi,2011). Estos se producen para satisfacer necesidades de la población siempre que al ser incorporados al intercambio permitan recuperar los costos de producción y realizar la ganancia asociada a la plusvalía que se genera en elprocesoproductivo $\mathrm{y}$, de esa forma, es apropiada monetariamente por el capital.Quienes quieren consumir esos productos debendisponer de la cantidad de dinero necesaria para ese intercambio. Por esa razón, solamente se producen los bienes que encuentran demanda solvente. En consecuencia, algunos bienes no se producirán, otros se destinarán a diferentes sectores sociales según sus ingresos y su consecuente capacidad económica de pagar por su consumo, es decir, de su solvencia.

En la medida que los bienes necesarios para la reproducción de la población están mercantilizados, las familias deben tener ingresos suficientes para acceder a cada uno deellos. En caso contrario, deberán dejar algunos de esos bienes fuera de su consumo.Esa capacidad económicano se define de manera polarizada (solvencia/insolvencia), sino que es un continuo entre posiciones extremas conotras intermedias. Una familia puede ser solventepara los consumos alimenticios cotidianos, pero no para los gastos que requiere la compra de una vivienda. Es un lugar común decir que la insolvencia frente a la necesidad de suelo-vivienda (y de las infraestructuras y demás componente de la ciudad) está asociada a las condiciones económicas de esos bienes: particularmente su muy altocosto. Pero obviamente, está fundamentalmente asociada a las condiciones de los ingresos sociales.

En suma, la mercantilización de la ciudad se concreta en su producción y consumo mercantiles, e indica que la posibilidad de la población deacceder(usar, poseer) a las condiciones de la urbanización depende de su solvencia. A contrario sensu, la consideración de la ciudad como derecho implica la posibilidad real de acceder a esos bienes como parte de la condición de ciudadanía,como la educación y la salud, desplazando su carácter de mercancía.

Si la solvencia fuese una situación generalno se presentaría la mencionada contradicción: las relaciones de mercado permitirían el acceso a la totalidad de los bienes necesarios para la reproducción de la población, incluyendo el asentamiento en la ciudad. Pero en las relaciones capitalistases estructural que los salarios no se determinen según las necesidades reales de reproducción de la población, sino por la consolidación de los procesos de acumulación económica que, justamente, se basan en la explotación. Recordemosque uno de los objetivos de 
Pírez, P.Una aproximación sociológica al derecho a la ciudad. Derecho y Ciencias Sociales. Mayo- Octubre 2019 № 21. (Derecho, ciudad y propiedad) Pgs 6-22. ISNN 1852-2971. Instituto de Cultura Jurídica y Maestría en Sociología Jurídica. FCJ y S. UNLP

las configuraciones de Estado de Bienestar fue evitar la exclusión del consumo, garantizando ingresos suficientes para ello. Esto se institucionalizó por medio de normas laborales y, particularmente, utilizando procedimientos colectivos de negociación capital-trabajo garantizados estatalmente. Cuando eso no fue suficiente, se utilizaron recursos fiscales conformando lo que se llamó el salario indirecto, que no fue otra cosa que transferencias desmercantilizadoras. ${ }^{6}$

Es evidente, en consecuencia, la importancia de la sustitución del consumo mercantil por el derecho, y de su concreción en procesos sociales que permitan acceder a los bienes de la urbanización. Lacontradicción entre derecho y mercantilización, entonces, puede ser atendida, dentro de ciertos límites por lo menos, por medio de una resolución social y política quegarantice la posibilidad generalizada de acceder a la ciudad, consumo no mercantil (o desmercantilizado), más allá de la solvencia/insolvencia.

Aceptado lo anterior, puede reconocerse la limitación de las meras declaraciones del derecho que no van acompañadas de decisiones políticas que ponen en marcha procesos sociales y económicos destinados a permitir (o garantizar) el acceso a la ciudad de manera independiente de las condiciones económicas. Esto significa evitar el obstáculo de la mercantilización con base en una declaración jurídica que concrete en ese sentido las condiciones de la ciudadanía. Declaración que, además, debe sostenerse en procesos económicos que habiliten el acceso a los bienes de la urbanización, más allá de la inicial disposición de recursos monetarios.

La sustitución del acceso mercantil por el derechose concretó históricamente con la intervención estatal por medio de políticas que permitieron la producción no mercantil de los bienes urbanos o la desmercantilización de su producción como, predominantemente, la desmercantilización del consumo, ampliando la solvencia de la población (Offe, 1990).

La producción no mercantil se orienta a satisfacer la necesidad de ciudad sin pasar por el mercado, sin buscar ganancia y, por lo mismo, sin requerir solvencia para ser consumida.Así, la producción de la ciudadqueda excluida de las relaciones de acumulación de capital. Es el caso de la producción estatal directa de vivienda o de otros bienes urbanos. El Estado puede operar como actor económico no mercantil dentro de un sistema de relaciones capitalistas dado que su reproducción no depende de la ganancia sino de su capacidad de obtener fiscalmente los recursos necesarios para ello. Por esa razón,el Estado puede hacer accesibles los bienes urbanos (u otros) sin retribución económica (consumo no mercantil). Puede distribuir esos bienes con

\footnotetext{
${ }^{6} \mathrm{Su}$ significación se aclara más adelante.
} 
Pírez, P.Una aproximación sociológica al derecho a la ciudad. Derecho y Ciencias Sociales. Mayo- Octubre 2019 № 21. (Derecho, ciudad y propiedad) Pgs 6-22. ISNN 1852-2971. Instituto de Cultura Jurídica y Maestría en Sociología Jurídica. FCJ y S. UNLP

base enuna definición de derecho de ciudadanía, así como lo hace, por ejemplo, con el derecho a la salud o a la educación. ${ }^{7}$

Además de la posibilidad de llevar adelante una producción no mercantil, el Estado desarrollaacciones de desmercantilización de la producciónque limitan las condiciones mercantiles de ciertos procesos productivos, sin eliminar la ganancia de los productores capitalistas. El resultado es la disminución del precio y por ende de la cantidad de recursos monetarios que deben utilizarse para su consumo, gracias a la transferencia de recursos fiscales al capital como exenciones impositivas, disminución de derechos de importación, apoyos financieros, etc. Como resultado, el precio del bien serámenor. Al mismo tiempo, el Estado puede llevar a cabo acciones dedesmercantilización del consumo: aumentandola solvencia de los consumidores con diferentes instrumentos que transfieren recursos fiscales (subsidios financieros, etc.). Como resultado, las familias que necesitan esos bienes pueden acceder a ellos sin disponer del dinero que sería necesario en una plena mercantilización. ${ }^{8}$

Los procesos mencionados suponen un acercamiento al consumo (acceso a los bienes) en términos de derechos, aunque con diferente significación.En el primero, con exclusión del capital privado en la producción de los bienes urbanos, cuyo consumo podrá realizarse sin aporte monetario, permitiendo una aplicación de los derechos de ciudadanía, en una clara sustitución del mercado por el derecho. En el segundo, el Estado limita la realización de la plusvalía en el intercambio, evitando su pleno traspaso a los precios y su afectación del consumo, gracias a latransferencia de recursos fiscalesque compensan la ganancia de los productores y/o la insolvencia de los consumidores. En este caso, se consolida al mercado al facilitar el consumoampliando la solvencia.

En los países capitalistas avanzados las situaciones mencionadas se consolidaron como parte de las políticas de bienestar entre la segunda posguerra y mediados de los años setenta del siglo $\mathrm{XX}$. En las sociedades latinoamericanas esas experiencias fueron mucho menos importantes y se dieron como parte de procesos de democratización del bienestar (Torre y Pastoriza, 2002). Con la reestructuración neoliberal, a partir de mediados de los años setenta del siglo XX, buena parte de esas situaciones se revirtieron, modificándose la orientación de las políticas estatales. Así, junto con el debilitamiento de los procesos estatales de producción no mercantil o

\footnotetext{
${ }^{7}$ Estas proposiciones no dicen nada sobre la significación estructural en relación con la reproducción de las relaciones capitalistas de los procesos que se mencionan.

8 No debemos confundir los procesos de desmercantilización del consumo con el debilitamiento de la acumulación. Se trata de captación fiscal de recursos cuyo uso contribuirá a disminuir el valor de la fuerza de trabajo y, por lo tanto, podrán ser una condición para favorecer la acumulación de capital en términos generales. Además, su verdadera significación no puede conocerse sin saber el origen de esos recursos (desde la ganancia, la renta o el salario, por ejemplo).
} 
Pírez, P.Una aproximación sociológica al derecho a la ciudad. Derecho y Ciencias Sociales. Mayo- Octubre 2019 № 21. (Derecho, ciudad y propiedad) Pgs 6-22. ISNN 1852-2971. Instituto de Cultura Jurídica y Maestría en Sociología Jurídica. FCJ y S. UNLP

desmercantilizada, se promovieron sus contrarios: la mercantilización de bienes y procesos previamente no mercantiles y la re-mercantilización de bienes y procesos desmercantilizados. El efecto fuela eliminación de las perspectivas de derecho a la ciudad, salvo el mantenimiento de acciones de desmercantilización del consumo que contribuyeron a consolidar la nueva mercantilización o re-mercantilización. El Estado tomó un papel de facilitador de esos negocios, contribuyendocon el fortalecimiento de la solvencia de sus consumidores. ${ }^{9}$

Los casos de mercantilización o re-mercantilización, que por sus efectos pueden no diferenciarse de los originalmente mercantiles, implican la incorporación en el mercado de bienes o procesos que estaban excluidos del mismo, como puede ser suelo comunal o ejidal (Salazar, 2013) o de propiedad o uso público; o debienes o servicios desmercantilizados que son privatizados (re-mercantilizados) (Pírez, 2009). También en estos casos lo normal es su consumo mercantil, pero no es posible excluir otras posibilidades. En primer lugar, una decisión estatal de mercantilización o re-mercantilización de la producción no impide que sea complementada con otra de desmercantilización del consumo de ese bien o servicio. Es también posible que un bien introducido estatalmente en el mercado sea adquirido mercantilmente con base en una desmercantilización solidaria. En la medida que se provoca una creciente mercantilización, esos bienes deben ser accedidos con base en la solvencia y, correlativamente, con el debilitamiento o exclusión de la garantía al derecho a la ciudad.Pero también es, no solamente posible sino muchas veces real, el acceso a los bienes o servicios remercantilizados, como infraestructuras y servicios urbanos,por medio del consumo no mercantilclandestino (Pírez, 2009).

La mercantilización de la producción de la ciudad tiende a repetirsemás de una vez en algunos sectores del territorio urbano. Para ello es condición la previa desurbanización, esto es la destrucción de las condiciones urbanas preexistentes. Esa desurbanización puede deberse al abandono involuntario de actores públicos y/o privados, o bien puede ser un efecto buscado. En principio, las consecuencias del deterioro urbano, más allá de sus causas, y los procesos de destrucción-construcción a que pueden dar lugar, suelen depender de las normas urbanas (planeación urbana) y de la efectiva aplicación que se haga de ellas. Esto es particularmente cierto con relación alas regulaciones sobre lo que se puede construir en un lugar que estádeteriorado o que puede deteriorarse.

La planificación urbana aparece como un elemento importante en la concreción, en una ciudad determinada, de definiciones más o menos abstractas del derecho a la ciudad. Por su medio

\footnotetext{
${ }^{9}$ Los programas de vivienda social (o urbanización social) de naturaleza predominantemente financiera son un buen ejemplo (Coulomb y Schteingart, 2006; Pírez, 2014; Rodríguez y Sugranyes, 2005; Zenteno, 2015).
} 
Pírez, P.Una aproximación sociológica al derecho a la ciudad. Derecho y Ciencias Sociales. Mayo- Octubre 2019 № 21. (Derecho, ciudad y propiedad) Pgs 6-22. ISNN 1852-2971. Instituto de Cultura Jurídica y Maestría en Sociología Jurídica. FCJ y S. UNLP

puedendefinir, por ejemplo, modalidades concretas de ejercicio de la propiedad privada sobre los bienes inmuebles (restricciones administrativas). Este componente de la planificación urbana, como limitación de la propiedad individual, suele estar relativamente legitimado en la sociedad. De allí su relevancia. ${ }^{10}$

Los grados de rigidez (o por el contrario de flexibilidad) de las normasy, particularmente, de sus controles, pueden operar como limitantes o facilitadores de los procesos de destrucciónconstrucción con los consecuentes efectos de exclusión de la población original.

Planteado el tema de esta forma, es evidente que se trata de una cuestión política en la que inciden los diferentes actores en juego y suspotencialidades para pesar en la toma de decisiones, tanto para la elaboración de las normas como para su aplicación y control.

El derecho a la ciudad, entendido en esta dimensión, dependerá de la relación entre normas y juego de fuerzas en la configuración del espacio urbano.

\section{El Derecho a la Ciudad y la propiedad privada}

En lo que estamos analizando, el derecho a la ciudad se opone a la tensión estructural hacia su acceso mercantil, pero no supone cuestionamiento alguno al derecho de propiedad.

Ahora bien, la propiedad privada, como hemos adelantado,es la segunda de las condiciones estructurales frente al derecho a la ciudad. Es estructural ya que el orden jurídico se impone a los actores sociales de una manera que, en principio, no puede ser soslayada ni modificada. ${ }^{11}$ Ese orden representa, en un momento dado, el resultado de relaciones de poder que se encuentran jurídicamente institucionalizadas, es decir sancionadas. Toda modificación posible, depende de un cambio en esas relaciones de poder, siempre dentro de condiciones paraque esa transformación esté definida por ese mismo ordenamiento con modalidades calificadas por su legalidad y, pretendidamente al menos, por su legitimidad. ${ }^{12}$

El orden jurídico "impone condicionamientos objetivos a los procesos sociales" y, por ello, “también forma parte de la realidad social” (Azuela, 1999:13). De manera particular,el derecho “impone condiciones reales al desenvolvimiento de las relaciones sociales de propiedad" que define más allá de sus contenidos económicos (Azuela, 1999:203).

Podríamos considerar al derecho a la ciudadcomouna regulación de las relaciones que determinan socialmente el acceso y goce de los bienes de la urbanización, y que se

\footnotetext{
${ }^{10}$ En el mencionado caso de Caballito en la Ciudad de Buenos Aires, las movilizaciones se orientaban a conseguir la limitación de las transformaciones con base en las normas urbanas. Y se consiguió la exclusión de algunas áreas del barrio de la posibilidad de construir torres de vivienda de gran tamaño (Cosacov, 2009).

${ }^{11}$ Como suele decirse, la violación de la ley implica su reconocimiento.

${ }^{12}$ Mencionamos aquí la posibilidad de la trasformación regular y no la que puede resultar de una posible ruptura del orden jurídico preexistente.
} 
Pírez, P.Una aproximación sociológica al derecho a la ciudad. Derecho y Ciencias Sociales. Mayo- Octubre 2019 № 21. (Derecho, ciudad y propiedad) Pgs 6-22. ISNN 1852-2971. Instituto de Cultura Jurídica y Maestría en Sociología Jurídica. FCJ y S. UNLP

da,concretamente,dentro de una relación jerárquica entre derechos. ${ }^{13}$ En esa jerarquía, el derecho a la ciudadtiende a confrontar con el derecho a la propiedad privada. Colisión de la que suele salir triunfante este último.

No es posible lograr una clara comprensión de la situación de esederecho si no se tiene en cuenta esa relación entre los derechos. En este apartado solamente exponemos este asunto, sin entrar en su desarrollo.

El derecho a la ciudades una suerte de derecho sin contenido, mientras que la propiedad tiene un contenido muy claro.Aquel derecho, que es una formulación conceptual asociada a las nociones de derechos de ciudadanía, es objeto de definición histórica para su posible reconocimiento positivo. Por lo general, las normas jurídicas reconocen un componente de ese derecho, particularmente el de la "vivienda digna". ${ }^{14}$ Podría discutirse la significación de esa fórmula (vivienda digna). Seguramente se concluiría que se refiere a un derecho que cubre mucho más que el techo. Es sin ninguna duda una unidad suelo-vivienda, de allí que el derecho a la vivienda incluye el derecho al acceso al suelo. Pero también, es más. La fórmula que utilizara Yujnovsky (1984) para definir a la vivienda, como conjunto de servicios habitacionales es una clara indicación de esa realidad compleja que se esconde detrás del término vivienda. El artículo 131 de la Constitución de la Ciudad de Buenos Aires agrega a la vivienda digna la existencia del derecho a un "hábitat adecuado".

Por otra parte, el derecho positivo no ha concretado el derecho a la ciudadfrente al derecho de propiedad. Por ejemplo, ante la falta de suelo para que las familias se asienten, el propietario de suelo no utilizado (vacante) no está obligado a disponer su propiedad (suelo de su propiedad) para permitir tal asentamiento. Y esto es así, más allá de que fuese posible hacerlo en las condiciones mercantiles de cada momento. El derecho de propiedad deja de lado la consideración de la necesidad de suelo de los no propietarios.El derecho civil no reconoce la existencia, en términos de sujetos de derecho, de los no propietarios. Como dice Azuela, la reforma de la constitución y las disposiciones dela Ley General de Asentamientos Urbanos de México de 1976no crearon "una garantía social en favor de los pobladores de las ciudades, ya que ni constituyen a los grupos más necesitados en sujetos jurídicos ni les otorgan derechos de contenido definido" (Azuela, 1999:35).

Podemos suponer que en esa difícil relación se ponen en juego tres dimensiones sociales fundamentales: el poder; la ganancia, particularmente la acumulación capitalista; y la cultura

\footnotetext{
${ }^{13}$ Para una perspectiva jurídica ver Galizzi, Orecchia y Petrelli (2014).

${ }^{14}$ Así lo dispone el artículo 14 bis incorporado en la Constitución Argentina en 1957 y el 131 de la Constitución de la Ciudad de Buenos Aires.
} 
Pírez, P.Una aproximación sociológica al derecho a la ciudad. Derecho y Ciencias Sociales. Mayo- Octubre 2019 No 21. (Derecho, ciudad y propiedad) Pgs 6-22. ISNN 1852-2971. Instituto de Cultura Jurídica y Maestría en Sociología Jurídica. FCJ y S. UNLP

como sistema de valoraciones socialmente predominantes.Las tensiones cristalizan en la institucionalización estatalde los procesos de apropiación del suelo, en su definición de la propiedad. Tal es el sentido común construido que, sin embargo, no se sostiene en referencia a una temporalidad más amplia y a una territorialidad igualmente mayor. ${ }^{15}$

En el capitalismo, la conjunción de esos elementos cristalizada en el derecho civil naturaliza a la propiedad por encima de los demás derechos. Consolida los resultados de los procesos originarios de apropiación de riquezas que, una vez sancionados por el Estado (jurídicamente), se vuelveninconmovibles. Un buen ejemplo son las apropiaciones coloniales del suelo por la potencia metropolitana, desconociendo las tenencias anteriores, con la subsiguiente distribución en propiedad individual, claramente asociada a la configuración de relaciones sociales articuladas políticamente. Esa fue la base económica de las elites dirigentes en América Latina, por lo menos hasta entrado el siglo XX. Grupos sociales que, con diferencias entre los países, mantienen un importante peso social y político. $^{16}$

Un indicador de la importancia actual otorgada al derecho de propiedad, particularmente inmobiliaria, es eltratamiento de las ocupaciones (ilegales) de tierras y de edificios. La situación en la Ciudad de Buenos Aires en los años 2000 es ilustrativa. Con base en el endurecimiento de la tipificación penal del delito de usurpación, ${ }^{17}$ el Gobierno de la Ciudad modificó las condiciones institucionales en una doble dimensión. En términos socioculturales consolidó una valoración negadora de un derecho a la ciudadpor encima de la propiedad, que se concretó en la utilización del delito de usurpación. En términos de gestión, se reordenaron los procedimientos, se traspasó ese delito desde el fuero federal al de la Ciudad (2008), se promovió la intervención del Ministerio Público Fiscal y se elaboró un protocolo para agilizar los desalojos. ${ }^{18}$ La Ciudad modificó también la política habitacional asistencial para vincularla

\footnotetext{
${ }^{15}$ La consolidación de la propiedad privada del suelo es una de las dimensiones de la configuración de la sociedad moderna, capitalista e industrial; por otra parte, subsisten en diferentes lugares del mundo, junto con la "nueva" propiedad privada, formas comunales de propiedad, por eso mismo excluidas de alguna manera del mercado (Aravena et al., 2014).

${ }^{16}$ Vale la pena marcar la excepción del caso mexicano con la sanción de un régimen diferente de propiedad como resultado de la ideología de la Revolución que se consolida en la Constitución de 1917 (Azuela, 1999).

${ }^{17}$ Según la reforma de 1995 el artículo 181 del Código Penal argentino dice: "Será reprimido con prisión de seis meses a tres años: $1^{\circ}$ el que por violencia, amenazas, engaños, abusos de confianza o clandestinidad despojare a otro, total o parcialmente, de la posesión o tenencia de un inmueble o del ejercicio de un derecho real constituido sobre él, sea que el despojo se produzca invadiendo el inmueble, manteniéndose en él o expulsando a los ocupantes; $2^{\circ}$ el que, para apoderarse de todo o parte de un inmueble, destruyere o alterare los términos o límites del mismo; $3^{\circ}$ el que, con violencias o amenazas, turbare la posesión o tenencia de un inmueble."

${ }^{18}$ En el año 2000 una modificación al Código Procesal Penal nacional, que fue retomado en el respectivo Código de la Ciudad de Buenos Aires, estableció un procedimiento rápido de desalojo para recuperar la propiedad usurpada de manera anticipada en un proceso penal por delito de usurpación en cualquier momento de este, o apenas abierta la investigación, siempre que sea verosímil la existencia de un derecho sobre el inmueble ocupado. Se configura una suerte de "desalojo exprés" (Arenaza, 2014:114).
} 
Pírez, P.Una aproximación sociológica al derecho a la ciudad. Derecho y Ciencias Sociales. Mayo- Octubre 2019 № 21. (Derecho, ciudad y propiedad) Pgs 6-22. ISNN 1852-2971. Instituto de Cultura Jurídica y Maestría en Sociología Jurídica. FCJ y S. UNLP

con los desahucios, a la vez que, junto a los lanzamientos promovidos judicialmente por propietarios privados, el Gobierno llevó a cabo desalojos administrativos de ocupantes de inmuebles públicos, como de inmuebles privados que corrían, en términos reales o no, riesgo de derrumbe (Pírez y Cosacov, 2016).Como resultado, la mera atribución del derecho de propiedad, de manera verosímil, desplaza jurídicamente la pretensión de legitimidad de la ocupación de alguien que puede tener una necesidad insatisfecha que, además está cubierta por un derecho reconocido a la inserción en la ciudad (como hábitat).

La propiedad encuentra rápidamente un escudo ideológico, jurídico y represivo que, en algunos casos,llega a provocar muertes en su defensa. ${ }^{19}$ Esto ayuda a entender por qué las tomas de suelo, que son un claro indicador de esa flagrante necesidad de suelo y vivienda, son institucionalmentedefinidas como cuestiones de seguridad (Cravino, 2014). En esa mirada, las ocupaciones sonhechos de inseguridad que deben ser enfrentados como tales: si no fueron evitados son reprimidos. Queda en claro que se protege la seguridad jurídica otorgada al derecho de propiedad. El derecho a la ciudadno tiene entidad suficiente como para que su incumplimiento sea considerado un asunto de inseguridad jurídica.

Si la ocupación en el Parque Indoamericano ${ }^{20}$ es observada con una perspectiva relativa al derecho a la ciudad, puede percibirse queel suelo que se ocupó eraun sectorque, si bien correspondía formalmente al Parque, estaba claramente abandonado. ${ }^{21}$ Además, ese suelo venía siendo mejorado y utilizado como área de recreación por los habitantes de los asentamientos informales de la zona. La ocupación, por lo tanto,estaría indicando que el hecho de la utilizaciónse antepuso al derecho de propiedad, en una mirada desde la necesidad. ${ }^{22}$

\section{Conclusiones}

Hemos caracterizadoel derecho a la ciudaden relación condos cuestiones centrales de la urbanización en las sociedades latinoamericanas: los procesos de producción-consumo mercantiles y las constricciones de la propiedad privada.

\footnotetext{
${ }^{19}$ Ese fue el resultado de la violenta represión utilizada para desalojar la ocupación del Parque Indoamericano en diciembre de 2010 en Buenos Aires, por familias que reivindicaban su Derecho a la Ciudad (Ferme, Vera y Zapata, 2014).

${ }^{20}$ Tengamos en cuenta que ese Parque no era formalmente tal, sino que estaba definido en las normas de usos de suelo como área de equipamiento (E). Esa diferencia formal, no modifica la función real de ese terreno y las consecuentes relaciones, valoraciones y usos de la población con el mismo (Agradezco el comentario de Hernán Petrelli).

21 "La presencia de basura y escombros, la falta de vegetación y de mobiliario urbano, eran claros indicadores de que aquel sector (...) parecía más un baldío que un parque" (Cravino, 2014:21).

${ }^{22}$ Entendiendo por tal, de manera particular, una de las lógicas de producción de la ciudad (Pírez, 1995).
} 
Pírez, P.Una aproximación sociológica al derecho a la ciudad. Derecho y Ciencias Sociales. Mayo- Octubre 2019 № 21. (Derecho, ciudad y propiedad) Pgs 6-22. ISNN 1852-2971. Instituto de Cultura Jurídica y Maestría en Sociología Jurídica. FCJ y S. UNLP

La primera vinculación, al definir tal derecho en referencia (contradictoria) con los procesos de producción-consumo de la urbanización, permite identificar, junto a las formas mercantiles otras diferentes. Esto es, la existencia de procesos de acceso a la urbanización, particularmente al suelo y la vivienda, por medio de formas no mercantiles. Por un lado, formas desmercantilizadas, históricamente cambiantes, que se sostienen en una declaración (jurídica) de reconocimiento de un derecho basado en la condición de ciudadanía y que se concretan en la existencia de mecanismos políticos y económicos. Esos mecanismos, diseñados como parte de la intervención estatal en las orientaciones de bienestar, dan lugar a diferentes modalidades de producción-consumo desmercantilizado que, con basa en transferencias fiscales del Estado,tienden a disminuir o eliminar la limitación de la condición de insolvencia y, al mismo tiempo, facilitar las relaciones mercantiles. En la medida que esos procesos permiten el acceso únicamente al suelo-vivienda (acceso a la urbanización), podría considerarse que, al limitar los efectos de exclusión en ese acceso, implicarían el reconocimiento parcial del derecho a la ciudad y el establecimiento de la condición de posibilidad de la existencia de un derecho a la ciudad pleno. Es evidente, por otra parte, que esas situaciones son definidas con base en relaciones dinámicas, siendo modificadas por componentes institucionales, sociales y económicos.Esto indica, además, que las concretas manifestaciones (jurídicas, políticas y económicas) del derecho a la ciudad dependen de las condiciones de cada una de las sociedades. Es posible, por ello, decir que se trata en cada caso de un derecho "realmente existente", para utilizar la fórmula aplicada para entender al neoliberalismo (Theodore, Peck y Brenner, 2009).

En este contexto, el derecho de propiedad aparece como una consolidación institucional de los procesos mercantiles de producción-consumo de la ciudad y, particularmente, de sus resultados en términos de acumulación económica.Opera como una limitación para la consolidación amplia del derecho a la ciudad. En nuestras sociedades, la garantía a la propiedad del suelovivienda excluye estructuralmente algunas posibles dimensiones del derecho a la ciudad, como sería la obligación de transferir suelo privado para la producción de vivienda social, aún en condiciones mercantiles.

Las dos dimensiones mencionadas, mercantilización y propiedad privada,son estructurales en tanto que se imponen a los actores sociales que deben aceptar esa existencia coercitiva que, en el mejor de los casos, restringe la significación del derecho que analizamos.

En la medida que las ciudades se estructuran en torno a los procesos mercantiles, no es el derecho a su acceso lo que permite la vida urbana plena. Por el contrario, es una cierta 
Pírez, P.Una aproximación sociológica al derecho a la ciudad. Derecho y Ciencias Sociales. Mayo- Octubre 2019 № 21. (Derecho, ciudad y propiedad) Pgs 6-22. ISNN 1852-2971. Instituto de Cultura Jurídica y Maestría en Sociología Jurídica. FCJ y S. UNLP

solvencia que, por otra parte, implica modalidades muy diferentes y desiguales de acceso a la ciudad y a sus bienes. Al mismo tiempo, en la medida que el suelo urbano y los bienes construidos sobre él son, ante todo, objeto de apropiación privada excluyente, sin limitaciones frente a situaciones de necesidad, los mecanismos mercantiles para su acceso se ven fortalecidos, con el uso, si fuere necesario de la coerción estatal.

Las relaciones entre ambos derechos, justificadas por la jerarquía entre ellos, generan contradicciones sociales que son enfrentadas por medio de diferentes luchas sociales que se orientan entre dos situaciones: la resolución inmediata de la necesidad de suelo-vivienda y urbanización (por medio de autoproducciones no mercantiles, fundamentalmente), y la reivindicación del derecho a una plena inserción social, dentro de los cuales se encuentra el derecho a la ciudad.

Esta última, en la medida que pretende el reconocimiento pleno de esederecho, implica no únicamente modificaciones jurídicas sino, particularmente,económicas, culturales y políticas. En definitiva, la existencia de ese derecho, y su aplicación por medio de instrumentos que exceden lo jurídico, como son las transferencias con recursos fiscales, suponen un cambio sustantivo en la sociedad. Podemos pensar que la plena significación del derecho a la ciudadconfigura una propuesta revulsiva, ya que implica la tensión para cambiar la ciudad de manera que todos/as tengan en ella el lugar que necesitan. Esto es, definirla necesidad como criterio institucional de acceso a la urbanización, garantizando la inclusión urbana. La ciudad como necesidad y el derecho como reconocimiento de esa necesidad y garantía de su satisfacción.

La postulación del derecho a la ciudadincluye una convocatoria a transformar la ciudad que apela a la dimensión dinámica de las luchas sociales, colocando estos hechos en relación con procesos sociales amplios, donde las relaciones políticas tienen un papel central y, por lo mismo, el Estado, en sus diferentes escalas. Pero, antes aún, debe reconocerse la importancia del peso social de ciertas definiciones que podemos llamar culturales (o ideológicas) entre las que se encuentra una noción particular de la propiedad y, en especial, de la propiedad del suelo. Este tema excede a la posibilidad de ser tratado en este artículo, pero vale la pena introducirlo. Mencionemos solamente dos aspectos. Por una parte, la relevancia que la propiedad de la tierra ha tenido en la conformación de la clase dominante en la Argentina que, por medio de la apropiación coercitiva de grandes extensione ${ }^{23}$ constituyó la base económica de esa clase e

\footnotetext{
${ }^{23}$ Legitimada como "conquista del desierto"
} 
Pírez, P.Una aproximación sociológica al derecho a la ciudad. Derecho y Ciencias Sociales. Mayo- Octubre 2019 № 21. (Derecho, ciudad y propiedad) Pgs 6-22. ISNN 1852-2971. Instituto de Cultura Jurídica y Maestría en Sociología Jurídica. FCJ y S. UNLP

introdujo criterios de legitimación social ${ }^{24}$. Tocar la propiedad parecería modificar esa legitimidad. Por otra parte, la no introducción de la noción de función social de la propiedad, y las dificultades que se encontraron cuando se presentaron proyectos en ese sentido, o se promovieron regulaciones del suelo que aplicaran esa valoración, ${ }^{25}$ que no fueron motivadas únicamente por los intereses económicos asociados con la propiedad del suelo. Estas cuestiones deben ser objeto de análisis más específicos.

Por último, es posible reconocer que el derecho a la ciudadpuede operar como una suerte de aglutinador de una serie heterogénea de contradicciones y luchas sociales y políticasorientadas, en definitiva, a la institucionalización de una amplia inserción material en la ciudad (suelovivienda) como base del acceso al conjunto de los bienes materiales e inmateriales de la reproducción social aglomerada (urbana). ${ }^{26}$

\section{Bibliografía}

Aravena, S. et al. (2014).La vivienda, entre el derecho y la mercancía. Las formas de propiedad en América Latina. Montevideo: Trilce-WE EFFECT.

Arenaza, S. (2014).Imperio de la ley, justicia por mano propia y negociación forzada del conflicto: el caso del Parque Indoamericano.En: Cravino, M. C. (Org.) Derecho a la ciudad y conflictos urbanos. La ocupación del Parque Indoamericano (pp. 113-128). Los Polvorines: UNGS.

Azuela, A. (1989).La ciudad, la propiedad privada y el derecho, México: El Colegio de México.

Cosacov, N. (2009). Dinámica del capital y movilización de vecinos. Aproximaciones a un análisis microespacial de un conflicto urbano en un barrio de la Ciudad de Buenos Aires.Intersticios. Revista Sociológica de Pensamiento Crítico,3 (2), 193-204.

Coulomb, R. y Schteingart, M. (Coords.) (2006).Entre el Estado y el mercado. La vivienda en el México de hoy. México: UAM-A-Miguel Ángel Porrúa.

Cravino, M.C. (2014). Causas y azares: la ocupación del Parque Indoamericano. En: Cravino. M.C. (Org.) Derecho a la ciudad y conflictos urbanos. La ocupación del Parque Indoamericano(pp.19-61).Los Polvorines: UNGS.

\footnotetext{
${ }^{24}$ La significación que se le da al "campo" dentro de la cultura nacional muestra esa operación.

${ }^{25}$ En la reforma al Código Civil y en la sanción de la ley “de acceso justo al hábitat" en la Provincia de Buenos Aires (Ley 14.449).

${ }^{26}$ Esto último, se conecta claramente con lo que Granier (2012) llama la mirada desde la ciudadanía que en el pensamiento de Lefebvre sustituye a la perspectiva proletaria, tal como mencionamos en la Introducción.
} 
Pírez, P.Una aproximación sociológica al derecho a la ciudad. Derecho y Ciencias Sociales. Mayo- Octubre 2019 № 21. (Derecho, ciudad y propiedad) Pgs 6-22. ISNN 1852-2971. Instituto de Cultura Jurídica y Maestría en Sociología Jurídica. FCJ y S. UNLP

Esping-Andersen, G. (1993).Los tres mundos del Estado del Bienestar, Valencia: Edicions Alfons El Magnànim-Generalitat Valenciana-Diputació Provincial de València.

Ferme, N., Vera, L. y Zapata, M.C. (2014). La toma del Parque Indoamericano. Un disparador para pensar a la política pública en movimiento. Perspectivas de Políticas Públicas, Año IV, (6).

Flanagan, W.G. (1993).Contemporary Urban Sociology.New York: Cambridge University Press.

Galizzi, D., Orecchia, M.L. y Petrelli, H. (2014).Capacidades estatales de intervención territorial. En:IPAP Líneas de Investigación 2014. Informe Final. Subsecretaría de Modernización del Estado.La Plata: Secretaría General de la Gobernación de la Provincia de Buenos Aires.

Garnier, J.P. (2012).El derecho a la ciudad desde Henri Lefebvre hasta David Harvey. Entre teorizaciones y realización. Ciudad es, (15), 217-225.

HIC-AL - Habitat International Coalition, América Latina (2008).El Derecho a la Ciudad en el mundo. Compilación de documentos relevantes para el debate. México: HIC.

Lefebvre, H. (1969).El derecho a la ciudad. Barcelona: Editorial Península.

Offe, C. (1990).Las contradicciones del Estado del Bienestar.Madrid: Alianza.

Pírez, P. (1995). Actores sociales y gestión de la ciudad. Ciudades [en línea], Año 7, (28), 8-14. Puebla: Red Mexicana de Investigadores Urbanos. Disponible en:

https://www.researchgate.net/publication/274313532_Actores_sociales_y_gestion_de la_ciuda $\underline{\mathrm{d}}$

Pírez, P. (2009).Las sombras de la luz. Distribución eléctrica, configuración urbana y pobreza en la Región Metropolitana de Buenos Aires. Buenos Aires: EUDEBA.

Pírez, P. (2010). Las tensiones en la producción de la ciudad y el Estado.Proposiciones, 37, 2230.

Pírez, P. (2014). La mercantilización de la urbanización. A propósito de los "conjuntos urbanos" en México.Estudios Demográficos y Urbanos[en línea],29, 3 (87), 481-512. Disponible en: http://www.redalyc.org/pdf/312/31235413002.pdf

Pírez, P. (2016a). Las heterogéneas formas de producción y consumo de la urbanización latinoamericana. Quid 16[en línea], 6, 131-167. Disponible en: https://publicaciones.sociales.uba.ar/index.php/quid16/article/view/2085 
Pírez, P.Una aproximación sociológica al derecho a la ciudad. Derecho y Ciencias Sociales. Mayo- Octubre 2019 № 21. (Derecho, ciudad y propiedad) Pgs 6-22. ISNN 1852-2971. Instituto de Cultura Jurídica y Maestría en Sociología Jurídica. FCJ y S. UNLP

Pírez, P. (2016b). Las heterogeneidades en la producción de la urbanización y los servicios urbanos en América Latina. Territorios[en línea], (34),87-112. Disponible en: http://www.redalyc.org/articulo.oa?id=35744556004

Pírez, P. (2018). Distribución, insolvencia y urbanización popular en América Latina. Revista de Geografía Espacios[en línea], No. 15, Vol.8, 67-93. http://revistas.academia.cl/index.php/esp/article/view/1034/1147

Pírez, P. y Cosacov, N. (en colaboración) (2016). El derecho a la ciudad y la reestructuración neoliberal en Buenos Aires: movilizaciones de sectores populares (“insolventes") y clases medias ("solventes"). En: Álvarez, L. (Coord.) Ciudadanía y nuevos actores en grandes ciudades(pp. 291-312). México: UNAM/UAM/Juan Pablos editor.

Polanyi, K. (2011).La gran transformación. Los orígenes políticos y económicos de nuestro tiempo. México: Fondo de Cultura Económica.

Rodríguez, A. y Sugranyes, A. (Editores) (2005).Los con techo. Un desafío para la política de vivienda social.Santiago de Chile: Ediciones SUR.

Salazar, C. (2012). Los ejidatarios en el control de la regulación. En: Salazar, C. (Coord.) Irregular. Suelo y mercado en América Latina(pp. 265-305). México: El Colegio de México.

Savage, M., Warde, A. y Ward, K. (2003).Urban Sociology, Capitalism and Modernity. New York: Palgrave Macmillan.

Theodore, N., Peck, J. y Brenner, N. (2009). Urbanismo neoliberal: la ciudad y el imperio de los mercados.Temas Sociales, (66), 1-11. Santiago de Chile: SUR.

Torre, J.C. y Pastoriza, E. (2002). La democratización del bienestar. En: Torre, J.C. (Dir.)Los años peronistas (1943-1955) (pp. 257-312). Buenos Aires: Sudamericana.

Yujnovsky, O. (1984).Claves políticas del problema habitacional argentino. 1955/1981.Buenos Aires: Grupo Editor Latinoamericano.

Zenteno Torres, E. (2015). Políticas de contraste a la marginalidad urbana. El caso de Santiago de Chile y Sao Paulo. En: Sehtman, A. y Zenteno, E.(Coord.) Continuidades, rupturas y emergencias. Las desigualdades urbanas en América Latina (pp. 159-174). México: CIALCPUEC-PEL-UNAM. 